\title{
Simultaneous STATCOM and Pitch Angle Control for Improved LVRT Capability of Fixed-Speed Wind Turbines
}

\author{
M. J. Hossain, Student Member, IEEE, H. R. Pota, V. A. Ugrinovskii, Senior Member, IEEE, and R. A. \\ Ramos, Senior Member, IEEE.
}

\begin{abstract}
A robust multivariable controller with the objective of enhancing the low-voltage ride-through (LVRT) capability of wind farms with fixed-speed induction generators is presented in this paper. The nonlinear dynamics of the wind generator is represented as a linear system and a norm-bounded nonlinear uncertain term, derived from the Cauchy remainder of the Taylor series. The designed robust controller provides acceptable post-fault performance for both small and large perturbations. Large disturbance simulations demonstrate that the designed controller enhances voltage stability as well as transient stability of the system during lowvoltage ride-through transients and thus enhances the LVRT capability of fixed-speed wind generators.
\end{abstract}

Index Terms-LVRT Capability, Fixed-Speed Wind Turbines, Linearization, Minimax LQG Control, Nonlinearity, Robust control, STATCOM and Pitch Angle Controls, Uncertainty.

\section{INTRODUCTION}

Power systems have grid codes which require wind turbines to remain connected to the system during power system faults. All wind turbine technologies, irrespective of type, employed in high-power wind farms, are required by the new grid codes in some countries to have a fault ridethrough capability for faults on the transmission system [1]. This is required in order to support the post-fault system recovery and also prevent the collapse of the power system due to the loss of generation. This becomes more significant as wind power penetration level increases. Typical LVRT requirements demand that wind farms remain connected to the grid for voltage levels as low as 5 percent of the nominal voltage for up to $140 \mathrm{~ms}$ [2].

Induction generators are preferred as wind generators for their low cost, low maintenance due to rugged brushless construction and asynchronous operation. Directly connected induction generators are not able to contribute to power system regulation and control in the same way as conventional field-excited synchronous generators. Induction generators need reactive power support to be connected to stiff grids. However, wind turbines are usually connected at weak nodes or at distribution levels where the network was not originally designed to transfer power into the grid [3]. This increases the need for dynamic reactive power support to ride-through severe faults.

M. J. Hossain, H. R. Pota, and V. A. Ugrinovskii are with the School of Engineering and Information Technology, UNSW@ADFA, Northcott Drive, Canberra, ACT-2600, Australia. e-mail: (m.hossain, h-pota, v.ougrinovski)@adfa.edu.au.

R. A. Ramos is with the Dept. of Electrical Eng., Engineering School of Sao Carlos, Av. Trabalhador Sancarlense, 400 13566-590 - Sao Carlos SP, Brazil. email: ramos@sel.eese.usp.br
When a disturbance or fault occurs, the voltage at the terminals of the wind turbine drops significantly, causing the electromagnetic torque and electric-power output of the generator to be greatly reduced. However, the mechanicalinput torque is almost constant during typical non-permanent faults and this causes the machine to accelerate. As the slip of the induction generator increases, the reactive power absorbed from the connecting power system increases. After the fault is cleared, a large amount of reactive power is drawn by the generators. If this is not available, the machine will speed out of control and get disconnected from the power system. To prevent these types of instabilities, STATCOMs can be connected to the system.

STATCOM technology adds the missing functionality to wind farms in order to become grid-code compliant [4]. STATCOMs are able to provide only reactive power control and to overcome this limitation, STATCOMs with battery energy storage systems (STATCOM/BESS) have emerged as promising devices for power system applications [5]. However, the BESS is based on chemical processes and thus it has some limitations such as slow response speed and short service life. Another alternative proposed in this paper is to simultaneously control the STATCOM (reactive power) and the pitch angle of the wind turbine (real power) to enhance the LVRT capability of induction generators in wind farms.

The conventional converter model of STATCOM is a multi-input multi-output nonlinear model, and the difficulty in controlling the converter is mainly due to its nonlinear behavior [6]. There are several ways of dealing with nonlinearities. A simple way is to use two separate proportionalintegral (PI) controllers to control the DC term and the reactive power [7]. However, in these cases, the response time is usually slow, and it is difficult to find appropriate PI parameters in a systematic way. Another method is to linearize the system around an operating point and then design a linear controller [8]. The two main problems with this method are: a) the controller is not effective for large disturbances; and b) the design is dependent on the operating point.

Several methods to control the pitch angle have been reported, e. g., the classical proportional-integral-derivative (PID) control [9], gain-scheduling control [10], robust control [11] and other nonlinear controllers [12]. However, most strategies are based on a linear wind turbine model around a specific operating point [13]. A linear quadratic Gaussian (LQG) method for designing pitch control has been discussed in [14]. It is known that the LQG controller provides good robustness in terms of gain margins and phase margins. However, these LOG controllers are unable 
to provide robustness against uncertainties in the operating conditions [15].

Robust control in power systems deals with the application of new techniques in linear system theory to enhance voltage and transient stability in power systems. The authors in [16] propose an $H_{\infty}$ pitch angle control design using linear matrix inequality (LMI) approach to reduce the fluctuating power of wind generators. A robust coordinated control method has been proposed to smooth the fluctuations of the generated power via pitch angle and battery chargedischarge control [17]. An $H_{\infty}$ controller has been designed by an LMI approach to achieve system robustness [17]. The nonlinearities of wind generators have not been explicitly considered in these papers in the design of robust linear controllers. To overcome these limitations of linear controllers, a nonlinear control technique for STATCOMs has been proposed to improve power quality and LVRT capability of wind turbines [18]. Nonlinear controllers usually have a more complicated structure and are harder to implement in practice. From an industrial point of view, it is preferable to use simple linear robust controllers in wind turbines; however, for robust performance, the nonlinearities need to be taken into account when the controllers are designed.

This paper presents an effective control design procedure for dealing with nonlinearities using a linearization method where the Cauchy remainder is included in the design process as a norm-bounded uncertainty [19]. The mean-value theorem allows to retain system nonlinearities in the system model; this improves modeling accuracy for representing nonlinear dynamics. This method enlarges the region over which the controller is effective, thus, enhancing the capability of the system to withstand large disturbances. Prior to the design of the controllers, a modal analysis has been carried out to identify the critical modes. By this approach, the potentially severe perturbations on the system are addressed in the controller design and this makes the proposed design procedure robust with respect to nonlinear behaviors in the system.

A minimax LQG design method is proposed for simultaneous STATCOM and pitch angle controls to augment the LVRT capability of wind turbines. Within the minimax optimal control design framework, robustness is achieved via optimization of the worst-case quadratic performance of the underlying uncertain system. The control design in this paper has been tested by simulations under various types of disturbances on a test system. Performance of the following two controllers is also compared to the controller proposed in this paper: (a) a robust STATCOM controller designed according to [20] and (b) a PI-based STATCOM controller proposed in [21].

Due to the relatively large number of existing wind farms with fixed-speed wind turbines ( although some of them are not obliged to have strict LVRT capability), it is important from a system-wide viewpoint that these wind farms comply with grid codes, even with respect to LVRT capability. The method proposed in this paper is able to make wind farms compliant with LVRT requirements and this is a major practical contribution of this paper.

The organization of the paper is as follows: Section III provides the mathematical modeling of the power system devices under consideration; test system and control objectives are presented in Section IV; Section V describes the linearization technique and the technique to obtain a bound for uncertainties; Section VI contains the essential details of the minimax LQG controller design technique as applied to our problem; and in Section VII, controller design algorithm and the performance of the controller are outlined. Concluding remarks and suggestions for future works are collected in Section VIII.

\section{LIST OF SYMBOLS}

Symbols in the order in which they appear.

$\begin{array}{ll}T_{a e}: \text { Aerodynamic torque } & \rho: \text { Air density } \\ A_{w t}: \text { Swept area } & \omega_{m}: \text { Rotor shaft speed } \\ c_{p}: \text { Power coefficient } & \lambda: \text { Tip-speed ratio } \\ \theta: \text { Pitch angle } & V_{w}: \text { Wind speed } \\ \text { R: Turbine rotor radius } & H_{m}, H_{G}: \text { Inertia constant } \\ K_{s}: \text { Torsion stiffness } & D_{m}, D_{G}: \text { Torsion damping } \\ \gamma: \text { Torsion angle } & f: \text { Normal grid frequency } \\ T_{e}: \text { Electrical torque } & N_{g}: \text { Gear ratio } \\ T_{m}: \text { Mechanical torque } & \omega_{G}: \text { Rotor speed of generator } \\ s: \text { Slip } & E_{q r}^{\prime}: \text { q-axis transient voltages } \\ R_{r}: \text { Rotor resistance } & T_{o}^{\prime}: \text { Transient time constant } \\ X_{s}: \text { Stator reactance } & X: \text { Rotor open-circuit reactance } \\ X_{r}: \text { Rotor reactance } & i_{d s}: \text { d-axis stator current } \\ X^{\prime}: \text { Transient reactance } & E_{d r}^{\prime}: \text { d-axis transient voltages } \\ V_{d s}: \text { d-axis stator voltage } & V_{q s}: \text { q-axis stator voltage } \\ v_{t}: \text { Terminal voltage } & i_{q s}: \text { q-axis stator current } \\ v_{d c}: \text { Capacitor voltage } & E_{d r}^{\prime}: \text { d-axis transient voltages } \\ C: \text { DC capacitor } & R_{C}: \text { Internal resistance of C } \\ \delta: \text { Rotor angle } & \alpha: \text { Firing angle of STATCOM } \\ m: \text { Modulation index } & P_{s}: \text { Power supplied to STATCOMs } \\ K_{m}: \text { Sensor constant } & T_{m}: \text { Sensor time constant } \\ x: \text { State vector } & \mathrm{A}, \mathrm{B}, \text { C, D: System matrices } \\ u: \text { Control input } & y: \text { Measured output } \\ \xi: \text { Uncertainty input } & \zeta: \text { Uncertainty output } \\ \beta: \text { Scaling parameter } & \phi, \psi: \text { Uncertainty gain matrix } \\ \tau: \text { Free parameter } & k: \text { inverter constant } \\ & \end{array}$

\section{POWER SYSTEM MODEL}

In this paper we consider a benchmark power system [22] to analyze the LVRT capability of fixed-speed wind turbines. The system consists of wind generators, STATCOMs and a constant MVA load. For stability analysis we include transformers and transmission lines in the reduced admittance matrix.

The nonlinear model of a wind turbine is based on a static model of the aerodynamics, a two mass model of the drive train and a third order model of the induction generator. The aerodynamic rotor torque is given as [22]:

$$
T_{a e}=\left(\rho / 2 \omega_{m}\right) A_{w t} c_{p}(\lambda, \theta) V_{w}^{3}
$$

where $\lambda=\frac{\omega_{m} R}{V_{w}}$ and $c_{p}$ is approximated by the following relation [23]:

$c_{p}=(0.44-0.0167 \theta) \sin \left[\frac{\pi(\lambda-3)}{15-0.3 \theta}\right]-0.00184(\lambda-3) \theta$.

Equation (1) shows that aerodynamic efficiency is influenced by variation of the blade pitch angle. Regulating the rotor blades provides an effective means to regulate or limit the turbine power during high wind speed or abnormal conditions. 


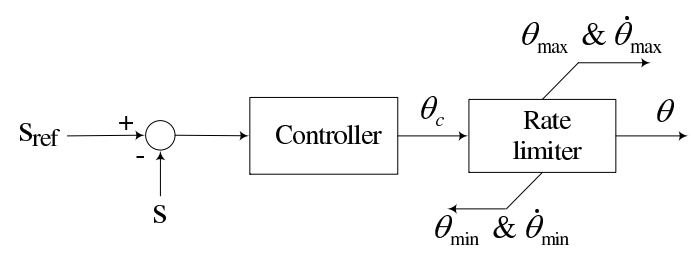

Fig. 1. Pitch angle control strategy.

Pitch control performs power reduction by rotating each blade about its axis in the direction of reducing the angle of attack. In comparison with the passive stall, the pitch control provides an increased energy capture at rated wind speed and above. Constant-speed wind turbines can be equipped with pitch drives which quickly increase the pitch angle when an acceleration of the rotor is detected. This reduces the mechanical power and consequently limits the rotor speed and the reactive power consumption after the fault. Fig. 1 depicts the pitch angle controller. In this work the pitch rate limit is set to $8(\mathrm{deg} / \mathrm{s}), \theta_{\min }=-5^{\circ}, \theta_{\max }=45^{\circ}, \dot{\theta}_{\min }=$ $-10(\mathrm{deg} / \mathrm{s}), \dot{\theta}_{\max }=10(\mathrm{deg} / \mathrm{s})$ and time constant is $0.2 \mathrm{~s}$.

The drive train attached to the wind turbine transfers the aerodynamic torque, $T_{a e}$, on the rotor into the torque on the low speed shaft, which is scaled down through the gearbox to the torque on the high-speed shaft. A two-mass drive train model of a wind turbine generator system (WTGS) is used in this paper. The drive train model can satisfactorily reproduce the dynamic characteristics of the WTGS. The dynamics of the shaft are represented as [22]:

$$
\begin{aligned}
\dot{\omega}_{m} & =\left(1 / 2 H_{m}\right)\left[T_{a e_{i}}-K_{s} \gamma-D_{m} \omega_{m}\right], \\
\dot{\omega}_{G} & =\left(1 / 2 H_{G}\right)\left[K_{s} \gamma-T_{e}-D_{G} \omega_{G}\right], \\
\dot{\gamma} & =2 \pi f\left(\omega_{m}-\left(1 / N_{g}\right) \omega_{G}\right) .
\end{aligned}
$$

The first inertia term, $H_{m}$, stands for the blades, hub and low-speed shaft inertia, while the second inertia term, $H_{G}$, stands for the high-speed shaft inertia.

For representation of fixed-speed induction generator models in power system stability studies, the stator flux transients can be neglected in the voltage relations [24]. A transient model of a single cage induction generator (IG) with the stator transients neglected and rotor currents eliminated is described by the following differential-algebraic equations [22], [24]:

$$
\begin{aligned}
& \dot{s}=\left(1 / 2 H_{G}\right)\left[T_{m}-T_{e}\right] \\
& \dot{E}_{q r}^{\prime}=-\left(1 / T_{o}^{\prime}\right)\left[E_{q r}^{\prime}-\left(X-X^{\prime}\right) i_{d s}\right]-s \omega_{s} E_{d r}^{\prime}, \\
& \dot{E}_{d r}^{\prime}=-\left(1 / T_{o}^{\prime}\right)\left[E_{d r}^{\prime}+\left(X-X^{\prime}\right) i_{q s}\right]+s \omega_{s} E_{q r}^{\prime}, \\
& V_{d s}=R_{s} i_{d s}-X^{\prime} i_{q s}+E_{d r}^{\prime}, \\
& V_{q s}=R_{s} i_{q s}+X^{\prime} i_{d s}+E_{q r}^{\prime}, \\
& v_{t}=\sqrt{V_{d s}^{2}+V_{q s}^{2}}
\end{aligned}
$$

where $X^{\prime}=X_{s}+X_{m} X_{r} /\left(X_{m}+X_{r}\right), X=X_{s}+X_{m}$, $T_{o}^{\prime}=\left(L_{r}+L_{m}\right) / R_{r}$, and $T_{e}=E_{d r}^{\prime} i_{d s}+E_{q r}^{\prime} i_{q s}$.

The STATCOM as shown in Fig. 2 is made up of a shunt transformer, a voltage source converter (VSC), a DC capacitor, a magnetic circuit and a controller. The reactive power exchange of STATCOM with the AC system is controlled by regulating the output voltage amplitude of VSC. If the amplitude is increased above that of the AC system, the current flows through the shunt transformer from

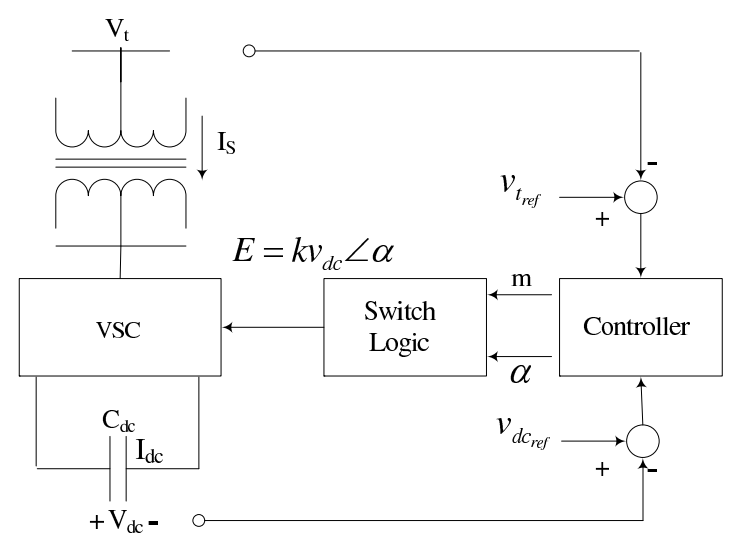

Fig. 2. STATCOM control strategy.

the STATCOM to the AC system, and the device generates reactive power (capacitive). If the amplitude is decreased to a level below that of the AC system, then the current flows from the AC system to STATCOM. The AC terminals of VSC are connected to the point of common coupling (PCC) through the leakage inductance of the coupling transformer.

The dynamics of this voltage source is governed by the charging and discharging of a large (nonideal) capacitor. The dynamics for STATCOM can be described by the following equation:

$$
\dot{v}_{d c}(t)=-P_{s} / C v_{d c}-v_{d c} /\left(R_{C} C\right),
$$

where $P_{s}$ is given by

$$
\begin{aligned}
& P_{s}=|E|^{2} G_{22}+|E|\left|V_{\infty}\right|\left[B_{23} \sin \alpha+G_{23} \cos \alpha\right] \\
& +|E|\left|E_{d r}^{\prime}\right|\left[B_{21} \sin (\delta-\alpha)+G_{21} \cos (\delta-\alpha)\right] \\
& +|E|\left|E_{q r}^{\prime}\right|\left[B_{21} \cos (\delta-\alpha)-G_{21} \sin (\delta-\alpha)\right]
\end{aligned}
$$

where $G_{23}$ and $B_{23}$ are the real and imaginary parts of the equivalent transfer impedances between the terminal buses of STATCOM and infinite bus, and $G_{21}$ and $B_{21}$ are between terminal buses of STATCOM and wind farm, $\alpha$ is the rotor angle of the wind generator, $E=k v_{d c} \angle \alpha$, is the STATCOM AC terminal voltage, $\alpha$ is the bus angle of the STATCOM in the reduced network, and $k=\sqrt{(3 / 8)} m$ is the constant and $m$ is the modulation index.

The STATCOM control strategy used in this paper is shown in Fig. 2. The pulse-width modulation (PWM) control technique is used because a PMW based STATCOM offers faster response and capability for harmonic distribution [25]. In this method, the compensation is achieved by measuring the rms voltage at PCC and the DC capacitor voltage. The output voltage (E) magnitude of the VSC relates to the DC side voltage and is also a function of the control phase angle and the modulation ratio of the PWM. The terminal voltage of STATCOM is measured using a transducer with first order dynamic:

$$
\dot{v}_{t m}=-v_{t m} / T_{m}+K_{m} v_{t},
$$

where $v_{t m}$ is the sensor output and $v_{t}$ is the voltage at the connection point of STATCOM, given by (10).

\section{TeSt System AND CONTROL TASK}

The test system shown in Fig. 3 consists of two main buses connected via two long parallel transmission lines. Wind turbines are connected to the first bus via transformers and the other bus is directly connected to the grid. Each induction 


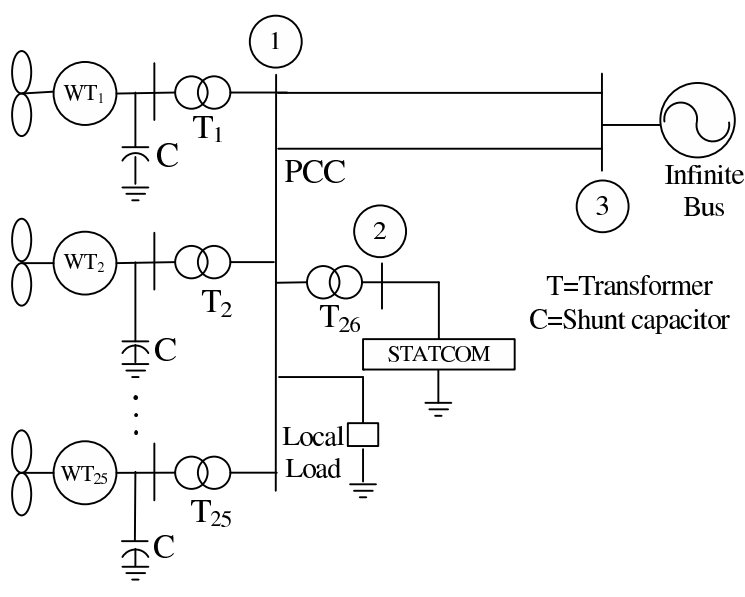

Fig. 3. Test System.

TABLE I

PARTICIPATION FACTORS

\begin{tabular}{|c|c|c|c|c|c|c|c|}
\hline$\triangle s$ & $\triangle E_{d r}^{\prime}$ & $\triangle E_{q r}^{\prime}$ & $\triangle \omega_{m}$ & $\triangle \omega_{G}$ & $\triangle v_{d c}$ & $\triangle v_{t m}$ & $\triangle \gamma$ \\
\hline 1.0 & 0.08 & 0.92 & 0.07 & 0.04 & 0.86 & 0.016 & 0.01 \\
\hline
\end{tabular}

generator works at the rated operating point and supplies 2 MW of active power. The wind farm considered in this paper has twenty-five wind turbines connected in parallel. We have used an equivalent aggregated wind generator model for the twenty-five turbines [26]. Wind farms, rated at about $50 \mathrm{MW}$ and above, are normally not allowed to operate under severe fault conditions and the addition of the STATCOM with appropriate control is expected to increase the stability margin as well as LVRT capability of the wind turbine. A 10 MVA STATCOM is connected to the wind farm bus in this test system. For the test system, the state vector is $x=\left[\omega_{m}, \omega_{G}, \gamma, s, E_{d r}^{\prime}, E_{q r}^{\prime}, v_{d c}, v_{t m}\right]^{T}$.

To appreciate the nature of the control task, we carried out the modal analysis for the open loop system with $50 \mathrm{MW}$ wind power and $10 \mathrm{MVA}$ STATCOM. The test system has an open-loop unstable mode corresponding to a positive eigenvalue at 0.1354 . The participation vector for the dominant mode is shown in Table I. The normalized participation vector indicates that the states $s, E_{q r}^{\prime}$, and $v_{d c}$ make significant contributions to the dominant mode. The above states are related to both reactive power and torque imbalance, which means that STATCOM and pitch angle controllers are appropriate choices to stabilize the system.

Effective feedback signals for the controller can be found by the methods of residues [27], where residues are the product of modal controllability and modal observability. The selection of the best feedback signals was made by comparison of the residues for different signals. Using the dominant residue method the most effective control inputs were found to be $u=[\triangle m, \triangle \alpha, \triangle \theta]^{T}$ with the feedback output $y=\left[\triangle v_{t}, \triangle v_{d c}, \triangle s\right]^{T}$. The other options considered for measured feedback output were real and reactive power output of the wind generator.

\section{LINEARIZATION AND UNCERTAINTY MODELING}

Conventionally, a linear controller is designed by neglecting the higher order terms of the Taylor series around an equilibrium point. This linearization technique limits the applicability of the linear model to small deviations from the equilibrium point. In this paper, we propose the use of a

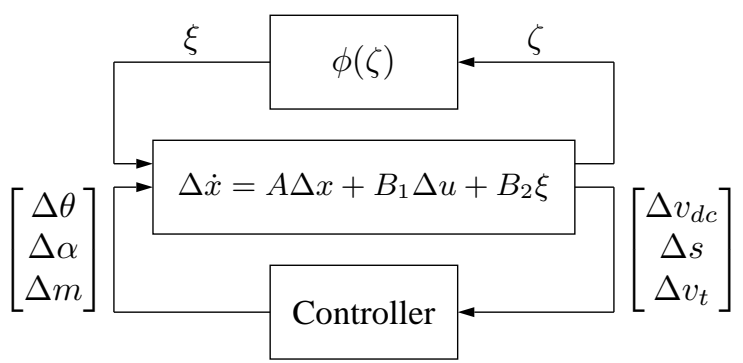

Fig. 4. Control block diagram.

linearization scheme which retains the contributions of the higher order terms in the form of the Cauchy remainder.

The reformulation proposed in this paper using Cauchy remainder allows us to represent the nonlinear power system models as:

$$
\begin{aligned}
\triangle \dot{x}(t) & =A \triangle x(t)+B_{1} \triangle u(t)+B_{2} \xi(t), \\
y(t) & \left.=C_{2} \triangle x(t)+D_{2} \xi(t)\right), \\
\zeta(t) & =C_{1} \triangle x(t)+D_{1} \triangle u(t)
\end{aligned}
$$

where $\triangle x$ is the state vector, $\Delta u$ is the control input, $y(t)$ is the measured output, $\xi$ is known as the uncertainty input, $\zeta$ is known as the uncertainty output. The procedure for obtaining the matrices in (14)-(16) and bounding uncertainty has been described in the rest of this section.

Let $\left(x_{0}, u_{0}\right)$ be an arbitrary point in the control space; using the mean-value theorem, the test system dynamics can be rewritten as follows:

$$
\dot{x}=f\left(x_{0}, u_{0}\right)+L\left(x-x_{0}\right)+M\left(u-u_{0}\right),
$$

where

$$
\begin{aligned}
& L=\left[\left.\frac{\partial f_{1}}{\partial x}\right|_{\substack{x=x^{* 1} \\
u=u * 1}}, \ldots,\left.\frac{\partial f_{8}}{\partial x}\right|_{\substack{x=x^{* 8} \\
u=u * 8}}\right]^{T}, \\
& M=\left[\left.\frac{\partial f_{1}}{\partial u}\right|_{\substack{x=x^{* 1} \\
u=u * 1}}, \ldots,\left.\frac{\partial f_{8}}{\partial u}\right|_{\substack{x=x^{* 8} \\
u=u * 8}}\right]^{T},
\end{aligned}
$$

where $\left(x^{* p}, u^{* p}\right), p=1, \cdots, 8$, denote points lying in the line segment connecting $(x, u)$ and $\left(x_{0}, u_{0}\right)$ and $f=$ $\left[f_{1}, \ldots, f_{8}\right]^{T}$ denotes the vector function on the right-hand side of the vector differential equations.

Letting $\left(x_{0}, u_{0}\right)$ be the equilibrium point and defining $\Delta x \triangleq x-x_{0}$ and $\Delta u \triangleq u-u_{0}$, it is possible to rewrite (17) as follows

$$
\begin{aligned}
\Delta \dot{x} & =\dot{x}-\dot{x_{0}}, \\
& =A \triangle x+(L-A) \triangle x+\left(M-B_{1}\right) \triangle u,
\end{aligned}
$$

where $A=\left.\frac{\partial f}{\partial x}\right|_{\substack{x=x_{0} \\ u=u_{0}}}$ and $B_{1}=\left.\frac{\partial f}{\partial u}\right|_{\substack{x=x_{0} \\ u=u_{0}}}$.

System (18) is shown as a block diagram in Fig. 4.

We introduce a signal $\xi$ such that

$$
(L-A) \triangle x+\left(M-B_{1}\right) \triangle u=B_{2} \xi(t),
$$

where

$$
\begin{aligned}
& B_{2}=\operatorname{diag}\left(1 / 2 H_{m}, 1 / 2 H_{G}, 0,1 / 2 H_{G},\left(X-X^{\prime}\right) / T_{0}^{\prime}\right. \\
& \left.\quad\left(X-X^{\prime}\right) / T_{0}^{\prime}, 1 / C, K_{m}\right), \text { and } \\
& \xi=\tilde{\phi}\left(\tilde{C}_{1} \triangle x\right)+\tilde{\psi}\left(\tilde{D}_{1} \triangle u\right) .
\end{aligned}
$$


The nonlinearities considered in this paper are only due to the dynamics of $s, E_{d r}^{\prime}, E_{q r}^{\prime}$ and $v_{d c}$, with this matrices $\tilde{C}_{1}$ and $\tilde{D}_{1}$ are chosen such that

$\tilde{C}_{1}=\left[\begin{array}{llllllll}0 & 0 & 0 & 1 & 0 & 0 & 0 & 0 \\ 0 & 0 & 0 & 0 & 1 & 0 & 0 & 0 \\ 0 & 0 & 0 & 0 & 0 & 1 & 0 & 0 \\ 0 & 0 & 0 & 0 & 0 & 0 & 1 & 0\end{array}\right], \quad \tilde{D}_{1}=\left[\begin{array}{lll}1 & 1 & 1 \\ 0 & 1 & 1 \\ 0 & 1 & 1 \\ 0 & 1 & 1\end{array}\right]$,

$(L-A) \triangle x+\left(M-B_{1}\right) \triangle u=B_{2} \xi$

where

$$
\zeta=\sqrt{\beta}\left(\tilde{C}_{1} \triangle x+\tilde{D}_{1} \triangle u\right), \phi=(1 / \sqrt{\beta})\left[\begin{array}{ll}
\tilde{\phi} & \tilde{\psi}
\end{array}\right] .
$$

In general, $x^{* p}, p=1, \ldots, 8$, are not known beforehand, it is difficult to obtain the exact value of $(L-A)$, but it is possible to obtain a bound on $\tilde{\phi}$ and $\tilde{\psi}$ over the operating range and parameter $\beta$ is chosen to ensure,

$$
\|\phi\|^{2} \leq 1
$$

From this, we have

$$
\|\xi(t)\|^{2} \leq \beta\left\|\left(\tilde{C}_{1} \triangle x+\tilde{D}_{1} \triangle u\right)\right\|^{2} .
$$

and we recover the norm bound constraints [28],

$$
\|\xi(t)\|^{2} \leq\|\zeta(t)\|^{2}
$$

The expressions for $\tilde{\phi}$ and $\tilde{\psi}$ are obtained in a similar way as in [19]. The system can now be written as

$$
\triangle \dot{x}=A \triangle x+B_{1} \triangle u+B_{2} \xi(t) .
$$

For systems satisfying the above condition (24), the minimax LQG controller ensures that the nonlinear system (14)-(16) is stable for all instances of linearization errors.

The output matrix for the controller is defined as $C_{2}=$ $[0,0,0,1,0,0,0,0 ; 0,0,0,0,0,1,0,0 ; 0,0,0,0,0,0,0,1]$. The theory requires that $D_{2} D_{2}^{\prime}>0$ [28]. This property is required by the design procedure but it does not represent any physical characteristics of the system; we choose the value of $D_{2}$ as small as possible. Equations (14)-(16) provide a new representation of the power system model which contains the linear part, and also another part with higher order terms. This formulation is used with the minimax LQG control theory to design the simultaneous STATCOM and pitch angle controllers for the wind farm.

\section{Minimax LQG CONTROL}

Minimax LQG methodology can be considered as a robust version of standard LQG controller design and it combines the advantages of both LQG and $H_{\infty}$ control [29]. Within the minimax optimal control design framework, robustness is achieved via optimization of the worst-case quadratic performance of the underlying uncertain system. This helps to achieve an acceptable trade-off between control performance and robustness of the system. The minimax LQG method described in [28], [29], for uncertain systems of the form shown in Fig. 4, is applied to the following stochastic version of the power system model (14)-(16):

$$
\begin{aligned}
\triangle \dot{x}(t) & =A \triangle x(t)+B_{1} \triangle u(t)+B_{2} \xi(t)+B_{2} w(t) \\
y(t) & \left.=C_{2} \triangle x(t)+D_{2} \xi(t)\right) \\
\zeta(t) & =C_{1} \triangle x(t)+D_{1} \triangle u(t)
\end{aligned}
$$

where $w(t)$ is a unity Gaussian white noise. The underlying physical system does not include noise-like inputs. The white noise term is a technical addition to enable the design of a robust output feedback controller which computes control inputs to drive the system to its equilibrium point in the presence of uncertain disturbances in the system such as those due to the effect of nonlinearities. It is suggested in [29, p. 342] that the optimal minimax LQG controller for the above system (26)-(28) is also a quadratically stabilizing robust controller for the deterministic system (14)-(16) with norm bounded uncertainty subject to (24). This motivates using the stochastic minimax LQG control design methodology to design a robust controller for the problem in this paper. As compared to the standard LQG control this minimax LQG controller provides robustness due to uncertainties which is important for the control design of wind generators.

In the minimax LQG problem for the stochastic system (26)-(28) the following quadratic cost functional is considered

$J=\lim _{T \rightarrow \infty} \frac{1}{2 T} E \int_{0}^{T}\left(\triangle x(t)^{T} R \triangle x(t)+\triangle u(t)^{T} G \triangle u(t)\right) d t$,

where $R \geq 0$ and $G>0, R \in R^{n \times n}, G \in R^{m \times m}$ and $E$ is the expectation operator. The work in [28], [29] considers the minimization of the maximum value of the cost over all uncertainties, such as $\phi$ in Fig. 4, satisfying an integral quadratic constraints (IQC) [29]. Uncertainties satisfy an IQC if they belong to the set $\phi_{\mathrm{IQC}}$ which consists of all $\phi$ such that for input signals $\zeta(t)$ and the output $\xi(t)=\phi(\zeta(t))$ there exists a constant $d>0$ and a sequence of times $\left\{t_{l}\right\}$, $l=1,2, \ldots, t_{l} \rightarrow \infty$, such that the following inequality holds for all $l$

$$
E \int_{0}^{t_{l}}\|\xi(t)\|^{2} d t \leq E \int_{0}^{t_{l}}\|\zeta(t)\|^{2} d t+d .
$$

The uncertainty class considered in this paper is a subset of the class of IQC uncertainties. This means that the optimum cost inf $_{\tau>0} V_{\tau}$ ) is an upper bound on the optimum cost for the norm-bounded uncertainty considered in this paper.

The optimum cost is the infimum of function $V_{\tau}$ obtained over all $\tau>0$. The function $V_{\tau}$ is

$$
\begin{aligned}
V_{\tau} & =\frac{1}{2} \operatorname{tr}\left[Y_{\infty} R_{\tau}+\left(Y_{\infty} C_{2}^{T}+B_{2} D_{2}^{T}\right) \Gamma^{-1}\right. \\
& \left.\times\left(C_{2} Y_{\infty}+D_{2} B_{2}^{T}\right) X_{\infty}\left(I-\frac{1}{\tau} Y_{\infty} X_{\infty}\right)^{-1}\right],
\end{aligned}
$$

where $\tau$ is a free parameter and the matrices $X_{\infty}$ and $Y_{\infty}$ are the solution to the following pair of parameter-dependent algebraic Riccati equations [28]:

$$
\begin{aligned}
& \left(A-B_{2} D_{2}^{T} \Gamma^{-1} C_{2}\right) Y_{\infty}+Y_{\infty}\left(A-B_{2} D_{2}^{T} \Gamma^{-1} C_{2}\right)^{T}- \\
& Y_{\infty}\left(C_{2}^{T} \Gamma^{-1} C_{2}-\frac{1}{\tau} R_{\tau}\right) Y_{\infty}+B_{2}\left(I-D_{2}^{T} \Gamma^{-1} D_{2}\right) B_{2}^{T}=0,
\end{aligned}
$$

and

$$
\begin{aligned}
& X_{\infty}\left(A-B_{1} G_{\tau}^{-1} \gamma_{\tau}^{T}+\left(A-B_{1} G_{\tau}^{-1} \gamma_{\tau}^{T}\right) X_{\infty}+\left(R_{\tau}-\right.\right. \\
& \left.\gamma_{\tau} G_{\tau}^{-1} \gamma_{\tau}^{T}\right)-X_{\infty}\left(B_{1} G_{\tau}^{-1} B_{1}^{T}-\frac{1}{\tau} B_{2} B_{2}^{T}\right) X_{\infty}=0 .
\end{aligned}
$$

Solutions of the above two Riccati equations (32) and (33) are required to satisfy the following conditions: $Y_{\infty}>0$, 
$\rho\left(X_{\infty} Y_{\infty}\right)<\tau, R_{\tau}-\gamma_{\tau}^{T} G_{\tau}^{-1} \gamma_{\tau} \geq 0, R_{\tau}=R+\tau C_{1}^{T} C_{1}$, $G_{\tau}=G+\tau D_{1}^{T} D_{1}, \gamma_{\tau}=\tau C_{1}^{T} D_{1}$.

The minimax LQG optimal controller $u^{*}$, with the $\tau^{*}$ at which the infimum of $V_{\tau}$ is reached, is given by [28]:

$$
\begin{aligned}
\dot{\hat{x}}_{c} & =\left(A-B_{1} G_{\tau^{*}}^{-1} \gamma_{\tau^{*}}^{T}\right) \hat{x_{c}}-\left(\left(B_{1} G_{\tau^{*}}^{-1} B_{1}^{T}-\frac{1}{\tau^{*}} B_{2} B_{2}^{T}\right)\right. \\
& \left.X_{\infty}\right) \hat{x_{c}}+\left(I-\frac{1}{\tau^{*}} Y_{\infty} X_{\infty}\right)^{-1}\left(Y_{\infty} C_{2}^{T}+B_{2} D_{2}^{T}\right) \\
& \times \Gamma^{-1}\left(y-\left(C_{2}+\frac{1}{\tau^{*}} D_{2} B_{2}^{T} X_{\infty}\right) \hat{x_{c}}\right) \\
u^{*} & =-G_{\tau^{*}}^{-1}\left(B_{1}^{T} X_{\infty}+\gamma_{\tau^{*}}^{T}\right) \hat{x_{c}} .
\end{aligned}
$$

The controller $u^{*}$ guarantees the following minimax property

$$
\sup _{\zeta \in \phi \text { IQC }} J\left(u^{*}, \zeta\right)=\inf _{u} \sup _{\zeta \in \phi \text { IQC }} J(u, \zeta)=\inf _{\tau} V_{\tau} .
$$

To obtain the controller for the system considered in this paper, the parameter, $\tau$, is chosen to minimize the quantity $V_{\tau}$. A line search is carried out to find the value of $\tau>0$ which attains the minimum value of the cost function $V_{\tau}$. This line search involves solving the Riccati equations (32) and (33) for different values of $\tau$ and finding that value which gives the smallest $V_{\tau}$ in (31). This allows us to construct a controller of the form in (35). In this paper, this suboptimal controller for the norm-bounded uncertainty is designed and implemented on the test system.

\section{CONTROLler DESIGN ALGORITHM AND PERFORMANCE EVALUATION}

The controller design steps are:

Step 1 From the simulations of the faulted system, obtain the range of the variation of state variables and form a volume $\Omega$ with corner points given by $\left(x_{0_{p}}-x_{f_{p}}\right)$ and $\left(x_{f_{p}}+x_{0_{p}}\right), p=1, \ldots, 7$, where $2 x_{f_{p}}$ is the largest variation of the $p^{\text {th }}$ state variable about its equilibrium value $x_{0_{p}}$.

Step 2 Obtain $\beta^{*}$ to satisfy (22)

$$
\beta^{*}=\max _{x^{* p} \in \Omega}\left\{\beta:\|\phi\|^{2}<1\right\} .
$$

Step 3 Check if there exists a feasible controller with $\beta=\beta^{*}$, i.e., if there exists a scalar $\tau$ such that there is a feasible solution to the coupled Riccati equations (32)-(33).

Step 4 If we obtain a feasible controller in the above step, either enlarge the volume $\Omega$, i.e., increase the operating region of the controller, or if we have arrived at the largest possible volume then perform an optimal search over the scalar parameter $\tau$ to get the infimum of $V_{\tau}$. If there is no feasible solution with the chosen $\beta=\beta^{*}$, reduce the volume $\Omega$ and go to Step 2. This process enables the selection of the largest range for which a feasible controller is obtained.

The term $x(t)^{\prime} R x(t)$, in the cost function (29), corresponds to the norm squared value of the nominal system output and $u^{\prime} G u$ is treated as a design parameter affecting controller gain. Although a certain amount of trial-and-error was needed, we have determined that the value $G=10^{-6} \times$ $\operatorname{diag}(1,1,1)$ and the matrix $R=\operatorname{diag}(2,1,1,3,1,1,3,1)$, in the cost function (29) ensured satisfactory performance
TABLE II

PERFORMANCE COMPARISON $(a)$ PROPOSED CONTROLLER $(b)$ ROBUST STATCOM AND $(c)$ PI-BASED STATCOM

\begin{tabular}{|c|c|c|c|c|c|c|}
\hline $\begin{array}{l}\text { STATCOM } \\
\text { (MVA) }\end{array}$ & \multicolumn{2}{|c|}{ (a) Proposed Controller } & \multicolumn{2}{l|}{ (b) Robust SISO } & \multicolumn{2}{|c|}{ (c) PI Control } \\
\hline & CS $(\mathrm{pu})$ & CCT (s) & CS $(\mathrm{pu})$ & CCT $(\mathrm{s})$ & CS $(\mathrm{pu})$ & CCT (s) \\
\hline 10 & 1.33 & 0.35 & 1.305 & 0.33 & 1.28 & 0.315 \\
\hline 25 & 1.43 & 0.418 & 1.35 & 0.405 & 1.31 & 0.396 \\
\hline 40 & 1.47 & 0.458 & 1.45 & 0.43 & 1.38 & 0.415 \\
\hline
\end{tabular}

of the controller. It can be seen that the state variables representing the rotor speed, slip and STATCOM DC voltage are given higher weight compared to the other state variables since we want quick controller response to compensate for speed and reactive power mismatch. Furthermore, the theory requires that $D_{2} D_{2}^{\prime}>0$ [28], so we chose $D_{2}=$ $10^{-6}[1,1,1,1]$.

We carried out several simulations to obtain the operating range during transients by applying large disturbances. The maximum value of $\phi$ is obtained over this region and not globally. If the maximum value of $\phi$ is evaluated globally, the calculation burden will be very high and it will lead to a conservative controller. For the given power system model, we are able to obtain a feasible controller with the value of $\beta=0.975$ for the range of $\left|\bar{s}-s_{0}\right| \leq 0.265 \mathrm{pu},\left|\bar{E}_{d r}^{\prime}-E_{d r 0}^{\prime}\right| \leq$ $0.42 \mathrm{pu},\left|\bar{E}_{q r}^{\prime}-E_{q r 0}^{\prime}\right| \leq 0.405 \mathrm{pu},\left|\bar{\omega}_{m}-\omega_{m 0}\right| \leq 0.436 \mathrm{pu}$, $\left|\bar{\omega}_{G}-\omega_{G 0}\right| \leq 0.523 \mathrm{pu},\left|\bar{\gamma}-\gamma_{0}\right| \leq 40^{\circ},\left|\bar{v}_{d c}-v_{d c 0}\right| \leq$ $0.365 \mathrm{pu},\left|\bar{v}_{t m}-v_{t m 0}\right| \leq 0.345 \mathrm{pu},\left|\bar{\theta}-\theta_{0}\right| \leq 35^{0}, \mid \bar{m}-$ $m_{0} \mid \leq 0.475$ and $\left|\bar{\alpha}-\alpha_{0}\right| \leq 45^{\circ}$. Although the designed controller is not globally stabilizing, simulations show that it stabilizes the post-fault dynamics for severe disturbances. The dominant mode for the closed loop is $-5.34 \pm i 21.86$ and the damping is 0.244 . From the eigenvalues, it can be seen that the closed loop system is well-damped.

Performance of the following three controllers was compared with respect to critical clearing time and critical speed: (a) PI-based STATCOM controller $(\triangle \theta=0)$, (b) single input Robust STATCOM controller $(\triangle \theta=0)$, and (c) two input and two output simultaneous STATCOM and pitch controller. The results of the comparison are shown in Table II. The critical clearing time and critical speed for the three-phase fault with a 10 MVA STATCOM are $0.35 \mathrm{~s}$ and 1.33 pu with simultaneous STATCOM and pitch controllers, compared with $0.33 \mathrm{~s}$ and $1.305 \mathrm{pu}$ with the single input robust STATCOM controller and $0.315 \mathrm{~s}$ and $1.28 \mathrm{pu}$ with the PI-based STATCOM. In this case, the gain of the tuned (trial and error method) PI controller is obtained as $K_{P}=$ 0.3 and $K_{I}=10.25$. It can be concluded that an appropriate combination of the voltage control by reactive power and the speed control by torque is an effective way of improving the stability and enhancing the fault-ride through capability of the relevant induction-generator-based wind turbines.

Performance of the proposed controller for a 10 MVA STATCOM was evaluated for (i) sudden outage of one of the lines serving the wind farm; and (ii) a three-phase fault at one of the parallel lines. Outage of one transmission line increases the equivalent line impedance and weakens the interconnection considerably. Due to the increase of the equivalent line reactance, extra reactive power is needed in order to maintain the voltage at the PCC. The generator speed and terminal voltage with the PI-based STATCOM, robust STATCOM controller and the proposed STATCOM 


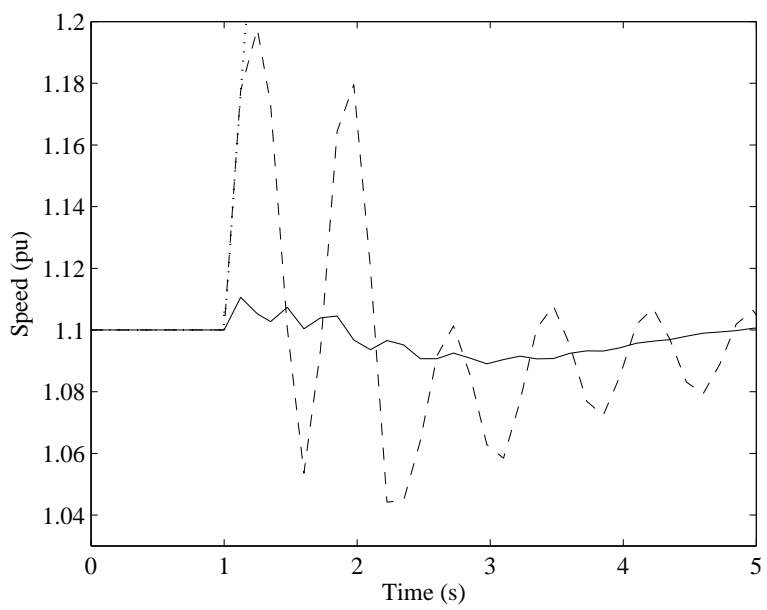

Fig. 5. Speed for the outage of one line. (Solid line simultaneous STATCOM and pitch angle controllers, dashed line robust STATCOM and dotted line PI-based STATCOM controller).

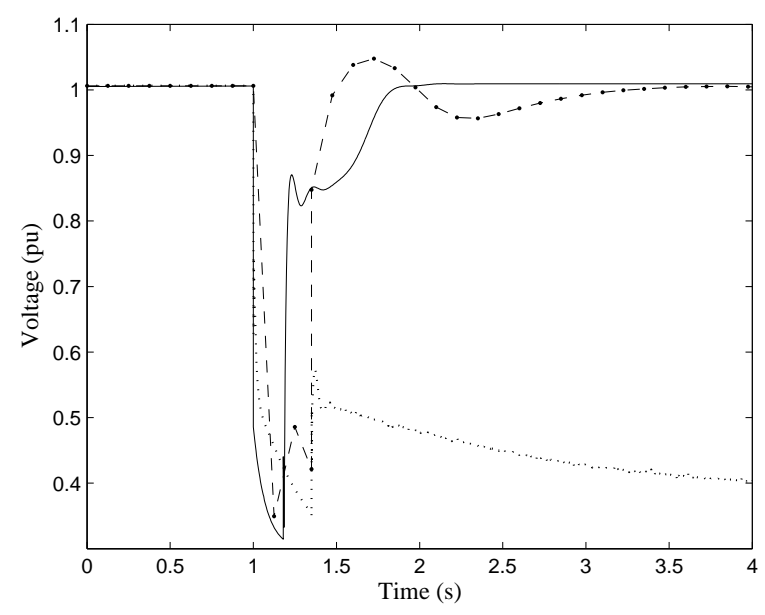

Fig. 6. PCC voltage for the outage of one line. (Solid line simultaneous STATCOM and pitch angle controllers, dashed line robust STATCOM and dotted line PI-based STATCOM controller).

and pitch controllers are shown in Figs. 5 and 6.

The proposed controller is able to stabilize the voltage as well as the induction generator speed with fault clearing time $0.35 \mathrm{~s}$. The speed of $1.32 \mathrm{pu}$ at the fault clearing is greater than the critical speed of $1.28 \mathrm{pu}$ as obtained for the PI controller with detailed simulations. Thus with the PI controller the speed continues to increase even after the fault is cleared. Furthermore, the voltage gradually decreases and the wind generators have to be disconnected from the grid to protect them and avoid voltage collapse.

A three-phase fault is applied to one of the long transmission lines at $1 \mathrm{~s}$ and cleared at $1.33 \mathrm{~s}$. The critical clearing time for the three phase fault is $0.35 \mathrm{~s}$ with STATCOM and pitch controllers, compared with $0.33 \mathrm{~s}$ with robust STATCOM controller and $0.315 \mathrm{~s}$ with PI-based STATCOM. Figs. 7 and 8 show the speed and terminal voltage of induction generator with the PI-based STATCOM, robust STATCOM controller and the proposed controller from which it can be seen that the proposed simultaneous STATCOM and pitch angle controllers perform better than the PI and single input robust STATCOM controller and results in a higher critical clearing time. The power system stabilizing

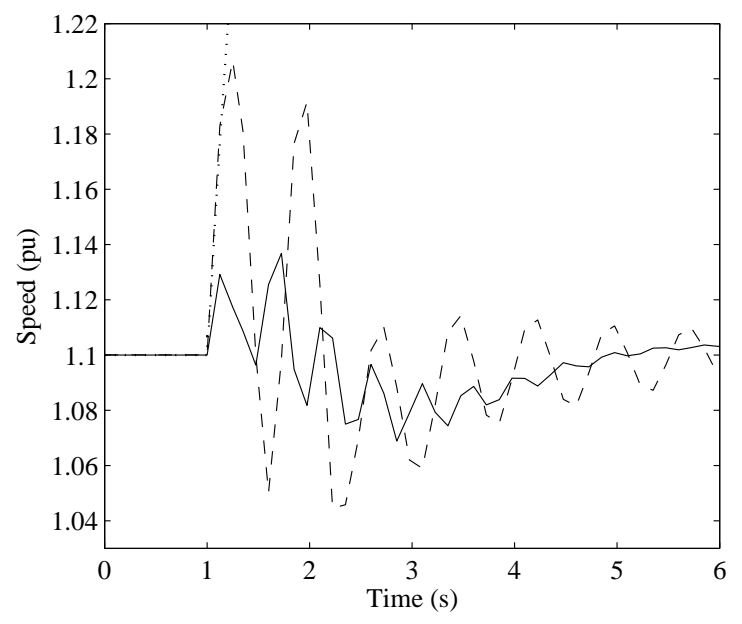

Fig. 7. Speed for the three-phase fault. (Solid line simultaneous STATCOM and pitch angle controllers, dashed line robust STATCOM and dotted line PI-based STATCOM controller).

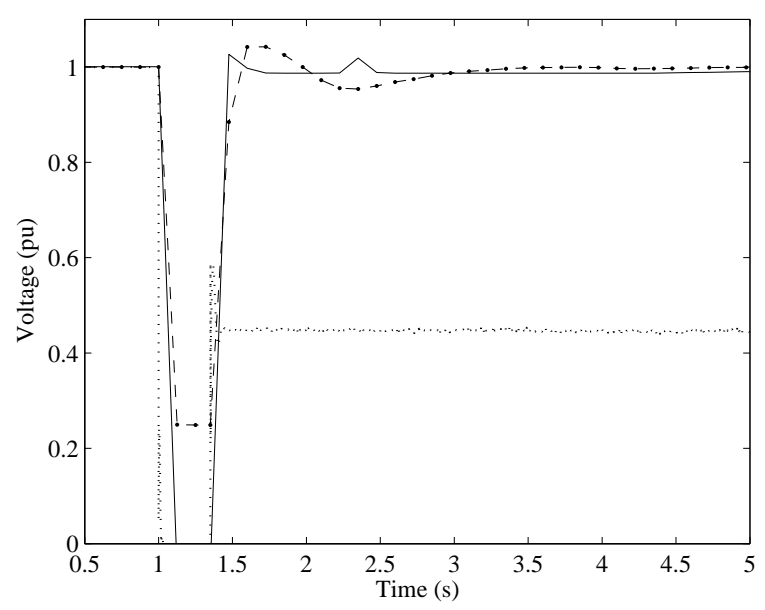

Fig. 8. PCC voltage for the three-phase fault. (Solid line simultaneous STATCOM and pitch angle controllers, dashed line robust STATCOM and dotted line PI-based STATCOM controller).

pitch angle controller controls the active power of the wind farm so the oscillations in the speed get damped, which is especially visible during the simulation time $1 \mathrm{~s}$ and $6 \mathrm{~s}$.

From our simulation analyses, we can conclude that simultaneous robust STATCOM and pitch angle controllers is almost as effective as robust STATCOM controller in restoring voltage but provides better performance in restoring speed. It is clear that controlling only the voltage by the robust STATCOM controller might not be enough to keep the system stable. Sometimes, in order to stabilize the system quickly, it could be necessary to use the pitch angle control. The combined strategy of robust STATCOM and pitch angle control is more effective in recovering the system operation, and such combined control makes the system ride-through the fault without having to disconnect the generators from the system. Both the designed simultaneous robust STATCOM and pitch angle controllers, and robust STATCOM controller designed according to our proposed technique always performs better than the conventional PIbased STATCOM controller. 


\section{CONCLUSIONS AND FUTURE WORKS}

In this paper, an algorithm to design a robust output feedback simultaneous STATCOM and pitch angle controller for a wind farm composed of fixed-speed turbines is proposed, with the objective of enhancing the LVRT capability of the farm. The designed controller guarantees stability if the system post-fault operating point is in the region for which the controller is designed. The results from the simulations show that the combination of the control of the dynamic reactive compensation and fast-acting pitch angle can improve the robustness of the overall solution applied to stabilize operation of the large wind farm and improve the fault-ride-through capability.

The controller order is the same as the order of the model so we need to do either model aggregation before controller design or controller order reduction after the design. The norm-bound on uncertain term is obtained numerically and not analytically. In spite of the preceding two limitations of the presented method, simulations show that it performs well for large disturbances.

The next step of this research is the incorporation of other important nonlinearities in the system (such as the nonlinear behavior of the torque in the wind turbine) and the extension of the generator models to include the stator transients, in such a way that the nonlinearities in the behavior of the stator variables are accounted for in a more accurate manner. Furthermore, a more precise model of the noise acting on the system (as opposed to the assumption of a Gaussian white noise) may yield better results with respect to the ones obtained in this paper, and this issue will also be investigated in future.

\section{REFERENCES}

[1] I. M. de Alegra, J. Andreu, J. L. Martn, P. Ibañez, J. L. Villate, and H. Camblong, "Connection requirements for wind farms: A survey on technical requirements and regulation," Renewable and Sustainable Energy Reviews, vol. 11, no. 8, pp. 1858-1872, October 2007.

[2] D. Bary, "Increasing renewable accessibility in Ireland," in 9th World Energy Congr., September 2004, pp. 1-10.

[3] M. R. Rathi and N. Mohan, "A novel robust low voltage and fault ride through for wind turbine application operating in weak grids," in 31st Annual Conference of IEEE Industrial Electronics Society, vol. 1, November 2005, pp. 2481-2486.

[4] M. Molinas, J. A. Suul, and T. Undeland, "Low voltage ride through of wind farms with cage generators: STATCOM versus SVC," IEEE Trans. on Power Electronics, vol. 23, no. 3, pp. 1104-1117, May 2008.

[5] S. M. Muyeen, R. Takahashi, T. Murata, J. Tamura, and M. H. Ali, "Application of STATCOM/BESS for wind power smoothening and hydrogen generation," Electric Power Systems Research, vol. 79, no. 2, pp. 365-373, February 2009.

[6] M. J. Hossain, H. R. Pota, V. Ugrinovskii, and R. A. Ramos, "A novel STATCOM control to augment LVRT capability of fixed-speed induction generators," in 48th IEEE Conference on Decision and Control, Shanghai, China, 16-18 December 2009, pp. 7843-7848.

[7] F. Blaabjerg, R. Teodorescu, M. Liserre, and A. V. Timbus, "Overview of control and grid synchronization for distributed power generation systems," IEEE Trans. on Power Electronics, vol. 53, no. 5, pp. 1398 1409, October 2006

[8] C. Shen, Z. Yang, M. L. Crow, and S. Atcitty, "Control of STATCOM with energy storage device," in IEEE Power Engineering Society Winter Meeting, 23-27 January 2000, pp. 2722-2728.

[9] V. Akhmatov, H. Knudsena, A. H. Nielsen, J. K. Pedersenb, and N. K. Poulsenc, "Modeling and transient stability of large wind farms," International Journal of Electrical Power and Energy Systems, vol. 25, no. 2, pp. 123-144, February 2003.

[10] F. D. Bianchi, R. J. Mantz, and C. F. Christiansen, "Gain scheduling control of variable speed wind energy conversion systems using quasiLPV models," Control Engineering Practice, vol. 13, no. 2, pp. $247-$ 255, February 2005
[11] R. Rocha and L. S. M. Filho, "A multivariable $H_{\infty}$ control for wind energy conversion system," in IEEE Conference on Control Applications, 23-25 June 2003, pp. 206-211.

[12] R. Chedid, F. Mrad, and M. Basma, "Intelligent control of a class of wind energy conversion systems," IEEE Trans. on Energy Conversion, vol. 14, no. 4, pp. 1597-1604, December 1999.

[13] P. Li, P. K. Keung, and B. T. Ooi, "Development and simulation of dynamic control strategies for wind farms," IET Renewable Power Generation, vol. 3, no. 2, pp. 180-189, December 2009.

[14] B. Connor, W. E. Leithead, and M. Grimble, "LQG control of a constant speed horizontal axis wind turbine," in IEEE Conference on Control Applications, vol. 1, August 1994, pp. 251-252.

[15] U. Shaked and E. Soroka, "On the stability robustness of the continuous time LQG optimal control," IEEE Trans. on Automatic control, vol. 30, no. 9, pp. 1039-1043, 1985.

[16] R. Sakamoto, T. Senjyu, T. Kaneko, N. Urasaki, T. Takagi, S. Sugimoto, and H. Sekine, "Output power leveling of wind turbine generator by pitch angle control using $H_{\infty}$ control," in IEEE PES Power Systems Conference and Exposition, October 2006, pp. 20442049.

[17] T. Senjyu, Y. Kikunaga, A. Yona, H. Sekine, A. Y. Saber, and T. Funabashi, "Coordinate control of wind turbine and battery in wind power generator system," in IEEE Power and Energy Society General Meeting, vol. 2, Pittsburgh, PA, 20-24 July 2008, pp. 1-7.

[18] W. Qiao and R. G. Harley, "Power quality and dynamic performance improvement of wind farms using a STATCOM," in IEEE Power Electronics Specialists Conference, June 2007, pp. 1832-1838.

[19] M. J. Hossain, H. R. Pota, V. Ugrinovskii, and R. A. Ramos, "Excitation control for large disturbances in power systems with dynamic loads," in IEEE Power and Energy Society General Meeting, Calgary, Canada, 26-30 July 2009, pp. 1-8.

[20] _ "Robust STATCOM control for the enhancement of fault ridethrough capability of fixed-speed wind generators," in IEEE MultiConference on Systems and Control, Saint Petersburg, Russia, 8-10 July 2009 , pp. $1505-1510$.

[21] M. Molinas, J. A. Suul, and T. Undeland, "Improved grid interface of induction generators for renewable energy by use of STATCOM," in International Conference on Clean Electrical Power, 2007, pp. 215222.

[22] T. Ackermann, Wind power in power systems. England: John Wiley and Sons, Ltd, 2005.

[23] E. S. Abdin and W. Xu, "Control design and dynamic performance analysis of a wind turbine-induction generator unit," IEEE Trans. on Energy Conversion, vol. 15, no. 1, pp. 91-96, March 2000.

[24] K. Nandigam and B. H. Chowdhury, "Power flow and stability models for IGs used in wind turbines," in IEEE Power and Energy Society General Meeting, vol. 2, June 2004, pp. 2012-2016.

[25] P. Giroux, G. Sybille, and H. Le-Huy, "Modeling and simulation of a distribution STATCOM using simulink's power system blockset," in 27th Annual Conference of the IEEE Industrial Electronics Society, 2001, pp. 990-996.

[26] L. Fernandez, C. Garcia, J. Saenz, and F. Jurado, "Equivalent models of wind farms by using aggregated wind turbines and equivalent winds," Energy Conversion and Management, Elsevier, vol. 50, no. 3, pp. 691-704, March 2009

[27] B. C. Pal, A. H. Coonick, and D. C. Macdonald, "Robust damping controller design in power systems with superconducting magnetic energy storage devices," IEEE Trans. on Power Systems, vol. 15, no. 1, pp. 320-325, February 2000.

[28] V. A. Ugrinovskii and I. R. Petersen, "Minimax LQG control of stochastic partially observed uncertain systems," SIAM Journal on Control and Optimization, vol. 40, no. 4, pp. 1189-1226, November 2001.

[29] I. R. Petersen, V. A. Ugrinovskii, and A. V. Savkin, Robust control design using $H_{\infty}$ methods. London: Springer, 2000.

M. J. Hossain (IEEE student member) was born in Rajshahi, Bangladesh, on October 30, 1976. He received the B.Sc. and M.Sc. Eng. degree from Rajshahi University of Engineering and Technology (RUET), Bangladesh, in 2001, and 2005, respectively, all in electrical and electronic engineering.

Presently he is doing $\mathrm{PhD}$ at the University of New South Wales at the Australian Defence Force Academy. His research interests are power systems, wind generator integration and stabilization, voltage stability, micro grids, robust control, electrical machine, FACTS devices and en- 
Hemanshu R. Pota received B.E. from SVRCET, Surat, India, in 1979, M.E. from the IISc, Bangalore, India, in 1981, and the Ph.D. from the University of Newcastle, NSW, Australia, in 1985; all in Electrical Engineering.

$\mathrm{He}$ is currently an associate professor at the University of New South Wales at the Australian Defence Force Academy, Canberra, Australia. He has held visiting appointments at the University of Delaware; Iowa State University; Kansas State University; Old Dominion University; the University of California, San Diego; and Centre for AI and Robotics, Bangalore. He has a continuing interest in the area of power system dynamics \& control, flexible structures, and UAVs.

V. A. Ugrinovskii (IEEE Member since 1996, Senior Member since 2002) was born in Ukraine in 1960. He received the undergarduate degree in applied mathematics and the Ph.D. degree in physics and mathematics from the State University of Nizhny Novgorod, Russia, in 1982 and 1990, respectively.

From 1982 to 1995 he held research positions with the Radiophysical Research Institute, Nizhny Novgorod. From 1995 to 1996 he was a Postdoctoral Fellow at the University of Haifa, Israel. In 1996 he has joined the School of Engineering and Information Technology, the University of New South Wales at the Australian Defence Force Academy, Canberra, and currently he is Associate Professor in the School. He is the coauthor of the research monograph Robust Control Design using $H^{\infty}$ Methods, Springer, London, 2000, with Ian R. Petersen and Andrey V. Savkin. His current research interests include decentralized and distributed control, stochastic control and filtering theory, robust control and switching control.

Rodrigo A. Ramos (S'97-M'03-SM'08) received the B.Sc.degree in 1997, the M.Sc. degree in 1999, and the Ph.D. degree in 2002 from Escola de Engenharia de Sao Carlos University of Sao Paulo (EESC/USP), Sao Carlos, Brazil.

$\mathrm{He}$ is currently an Assistant Professor at EESC/USP. His research interests are in the fields of power system dynamic performance, stability and robust control 